\title{
Association between migration and cognitive status among middle-aged and older adults: a systematic review
}

Hanzhang $X u^{1,2^{*}}$, Yinan Zhang ${ }^{3}$ and Bei Wu ${ }^{4}$

\begin{abstract}
Background: This study aimed to synthesize the current literature examining the association between migration and cognitive function among middle-aged and older adults.

Methods: We used the PRISMA as a guideline for this systematic review and searched the following databases: PubMed, CINAHL, EMBASE, and Global Health.

Results: Twenty-five published studies were included. Twenty-two studies were focused on international migrants, while only 3 studied internal migrants. Fourteen studies were conducted in the United States, followed by UK $(n=2)$, Israel $(n=2)$, India $(n=2)$ and other countries like Canada and Australia. Some studies showed that middleaged and older migrants demonstrated poorer cognitive function comparing to non-migrants in hosting places; while other studies indicated no association between migration and cognitive function. A higher level of acculturation was associated with better performance on cognitive function tests among migrants.

Conclusion: It is unclear how or whether migration and cognitive function are related. The quality of current literature suffered from methodological deficiencies. Additional research is needed to examine the linkages using more comprehensive measures of migration and cognitive function.
\end{abstract}

Keywords: Cognition, Memory disorder, Dementia, Emigration, Immigration

\section{Background}

Migration, defined as the geographic movement of people across a specified boundary for the purpose of establishing a new permanent or semi-permanent residence, is one of the three demographic components (i.e. birth, death, and migration) used to assess population changes [1]. Increasing migration both within countries and internationally has been observed globally [2]. It is estimated that the number of international migrants reached 232 million in 2013, and another 740 million were internal migrants [2]. Overall, migrants move from less developed areas (e.g. rural setting, developing countries) to more developed areas (e.g. urban setting, developed countries) [2].

\footnotetext{
* Correspondence: hanzhang.xu@duke.edu

${ }^{1}$ Duke University School of Nursing, Durham, NC, USA

${ }^{2}$ Duke Global Health Institute, Duke University Medical Center, Durham, NC, USA

Full list of author information is available at the end of the article
}

An increasing number of migrants are entering into old age, and many of them suffer from deterioration of health outcomes in later life, including cognitive decline $[3,4]$. Understanding the association between migration and cognitive function would provide better knowledge of risk factors related to cognition and help develop strategies and programs to promote healthy aging among the migrant populations.

Migration is a major life event and its associated changes, including changes in socioeconomic status (SES), lifestyle, and environment, may have a significant impact on health status in later life (see Fig. 1) [5, 6]. A number of studies have shown that adulthood SES such as education, income, and occupation are protective factors in cognitive decline [7-10]. Migration may result in an improvement in an individual's socioeconomic status (SES). For example, rural-to-urban migrants tend to have more exposure to education opportunities, which may positively influence their cognitive function in late 


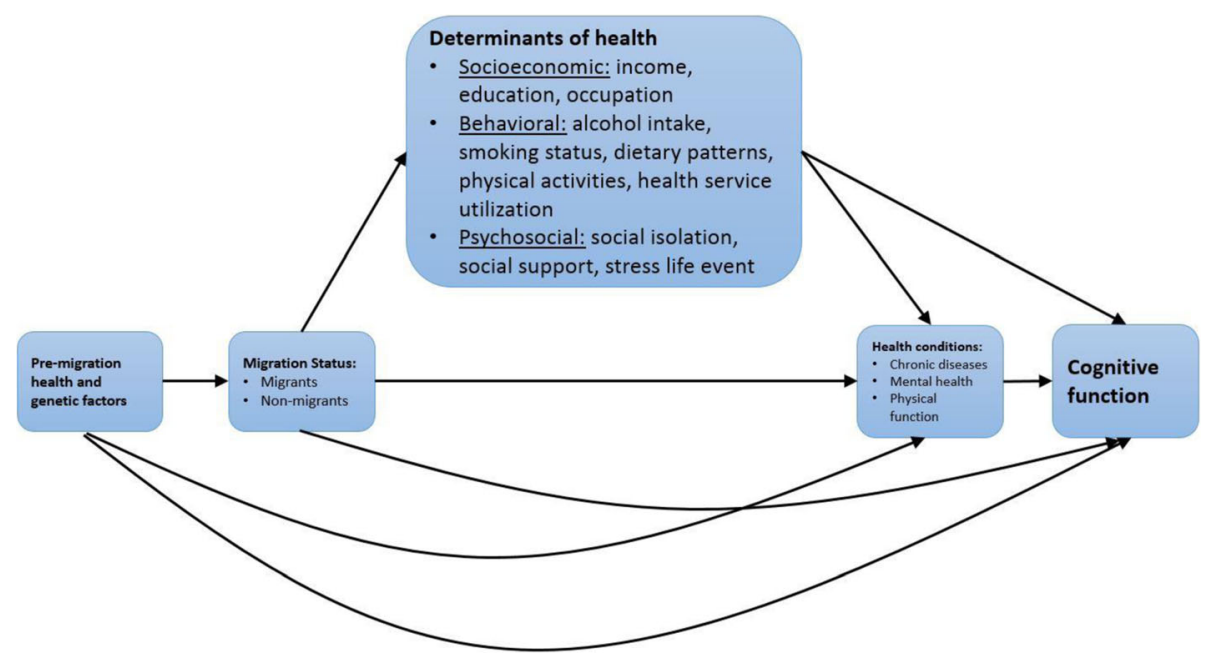

Fig. 1 Potential linkages between migration and cognitive function

life [11]. Moreover, these positive effects may lead to improvement in access to care and better management of chronic conditions, which could contribute to better cognitive function over time [12].

Behavioral changes have been observed in the migrant population as well. When migrating from a rural to an urban setting, and from a low and middleincome country to a high-income country, westernized life styles are often adopted [13-15]. Migrants are thought to be adopters of high-risk lifestyle that include calorie-intensive dietary patterns and physical inactivity [16]. They are often exposed to mechanized or sedentary employment and tobacco use [17-19]. These high-risk lifestyles are associated with the development of chronic diseases, including cardiovascular diseases, and poor cognitive function [20-22].

In addition, migrants often experience stressors during and after the migration process [23]. The separation from family is likely to be associated with reduced level of social support and size of social network. The perceived discrimination and a lack of sense of belonging in their destination may contribute to social isolation and development of depressive symptoms [24, 25], which can affect late-life cognitive function [26].

Currently, it remains to be unknown whether adult migrant population has better cognitive function compared to individuals who do not migrate. This significant gap in our knowledge is concerning given the rapidly increasing aging and migrant population. Therefore, we conducted a systematic review in order to examine the association between migration and cognitive function and provide direction for future research. If there is an association, this finding will have potential implications for clinical practices as well as health policies.

\section{Methods}

This literature review was conducted using the Preferred Reporting Items for Systematic Reviews and MetaAnalyses as a guideline [27]. We searched PubMed on January 19, 2016 using the following terms: ("Memory Disorders" [Mesh] OR "Cognition" [Mesh] OR "Cognition Disorders" [Mesh] OR "Dementia" [Mesh]) AND ("emigration and immigration"[MeSH Terms] OR ("emigration" [All Fields] OR "immigration" [All Fields]) OR "emigration and immigration" [All Fields]) OR ("emigrants and immigrants" [MeSH Terms] OR ("emigrants" [All Fields] OR "immigrants" [All Fields]) OR "emigrants and immigrants" [All Fields]) OR "residential mobility" [MeSH Terms] OR "transients and migrants" [MeSH Terms] OR "migration" [All Fields] OR "migrant" [All Fields] OR "mass-migration" [All Fields] OR "Human Migration" [Mesh] OR "Population Dynamics" [Mesh]). Four additional datasets (EMBASE, Global Health, PsycInfo, and CINAHL) were also searched using similar terms. The search procedures are described in the Fig. 2. Results were limited to human subjects and English language, which yielded a total of 1674 articles. We applied two rounds of exclusionary criteria to identify non-qualifying articles that did not involve the adult population, did not examine cognitive function, did not focus on migration, or were not empirical studies. We first excluded 1511 articles by reviewing titles and abstracts, and 163 articles remained. We further eliminated 141 articles by scanning full text and we retained 22 articles. To these were added 3 articles culled from article reference lists, resulting in a total of 25 studies.

Two independent reviewers assessed the eligibility of each articles, extracted the information, and evaluated the quality of each study based on a set of established criteria. Disagreements between the two independent reviewers were discussed and resolved with the third 


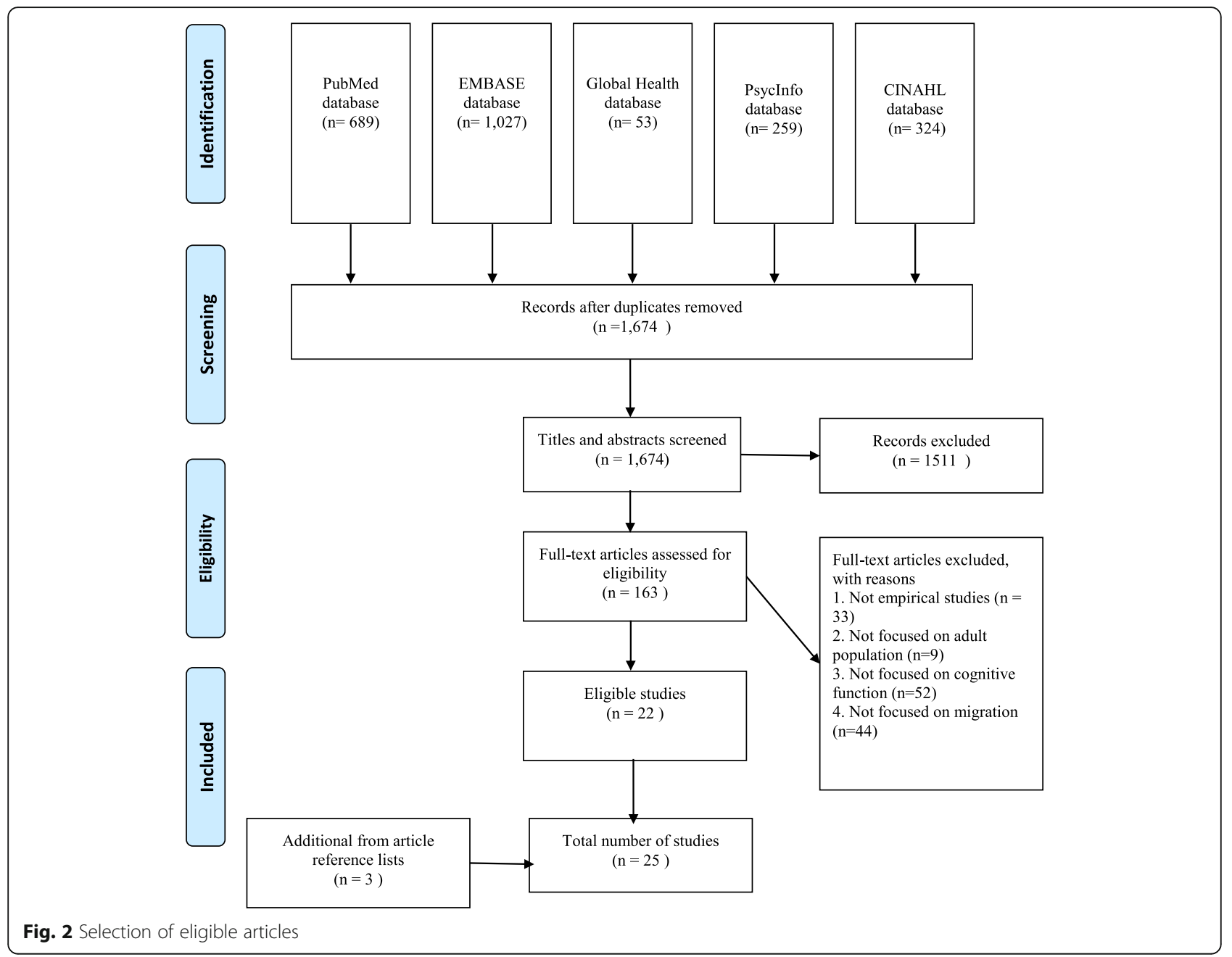

reviewer. Information extracted from each eligible article included author and date of publication, study design, sample and location, outcome measures, and key findings. Given the heterogeneity in study design, definitions of migration, and outcome measures used, completing a meta-analysis was considered inappropriate.

\section{Results}

\section{Characteristics of the eligible studies}

A total of 25 articles were included in this review (Table 1), of which 22 were focused on international migrants, while only 3 studied migrants within their home country. Fourteen studies were conducted in the United States, followed by UK $(n=2)$, Israel $(n=2)$, and India $(n=2)$. Other study sites included Australia $(n=1)$, Denmark $(n=1)$, Canada $(n=1)$, the Netherland $(n=1)$, and Belgium $(n=1)$. Among the 14 studies conducted in the United States, 8 of them were focused on Mexican Americans. The majority of the studies were community-based, but two studies included participants from both community and institutions [28, 29].

Only 9 of the 25 articles applied longitudinal design. The follow-up period of the longitudinal studies varied from 1 year [30] up to 23 years [31]. Nine studies used a secondary data analysis approach, and 4 of these analyzed the data from the Hispanic Established Populations for the Epidemiologic Study of the Elderly [32-35]. Sample size also ranged from small $(N=81)$ [36] to large $(N=12,008)$, with the latter including samples from several large datasets, such as the Sacramento Area Latino Study on Aging and the Mexican Health and Aging Study [37].

\section{Measures of cognitive function}

Assessment of cognitive function included use of standard clinical diagnostic criteria of dementia, information from medical records, epidemiological screening measures, and a variety of neuropsychology measures. Four studies 


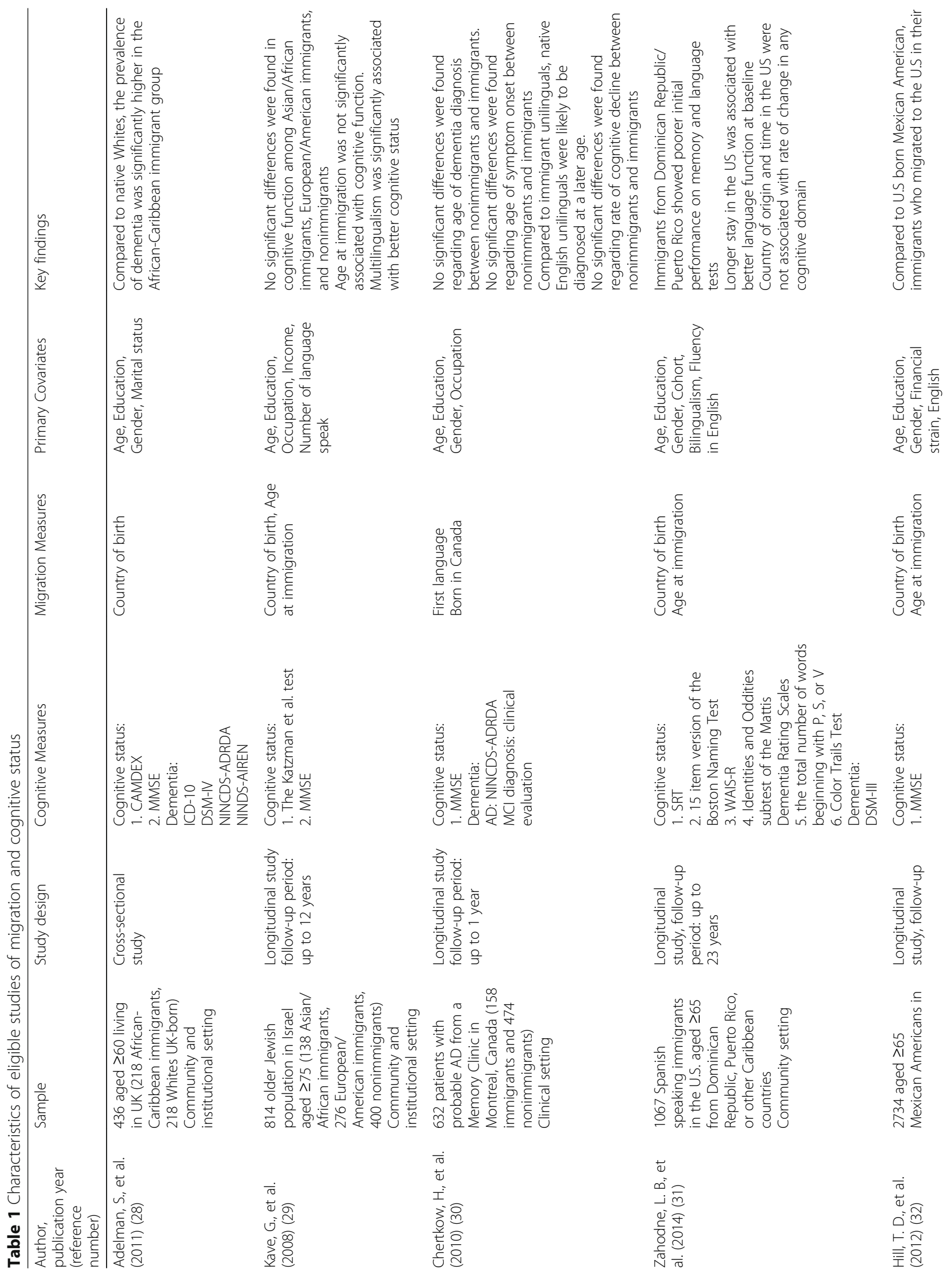




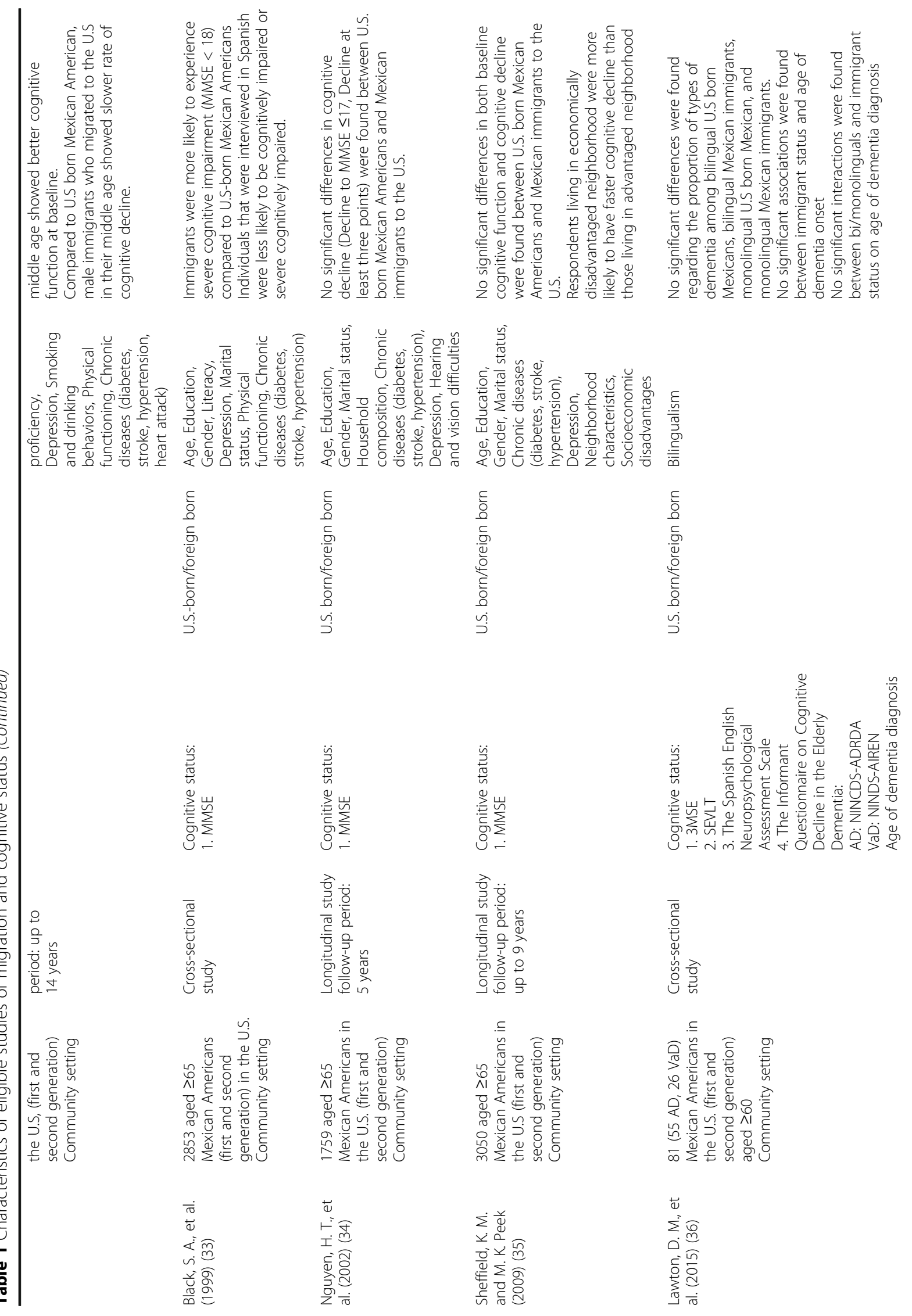




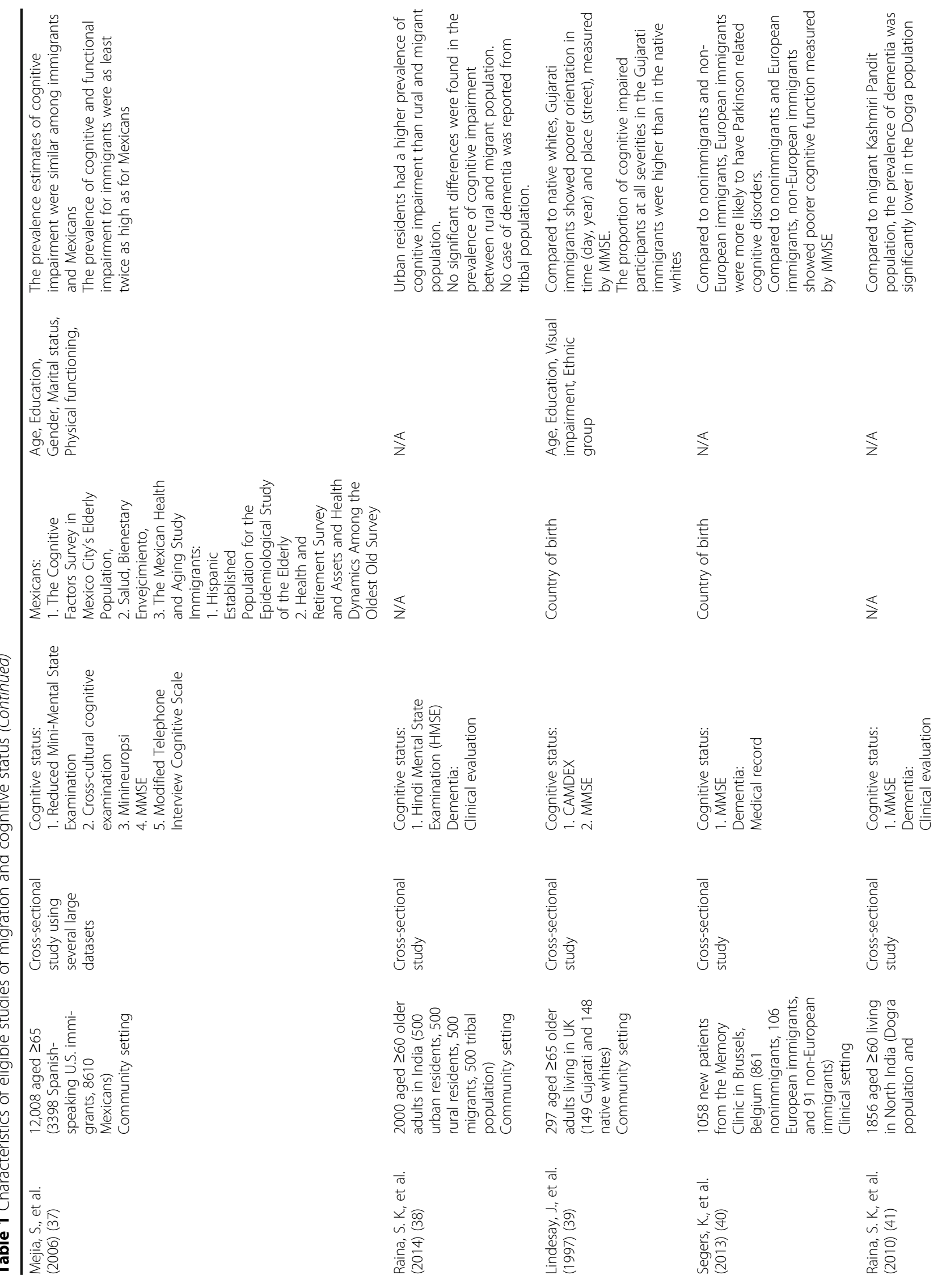



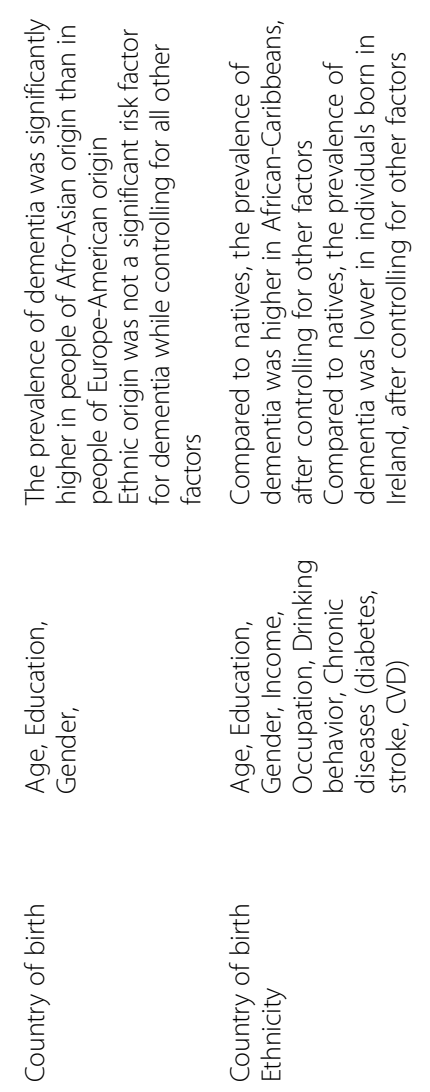

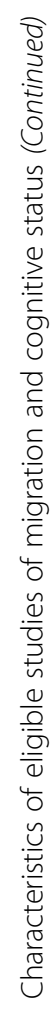

橧

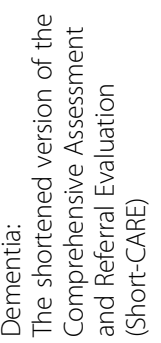

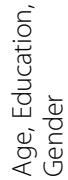

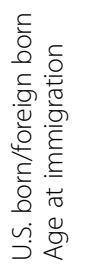

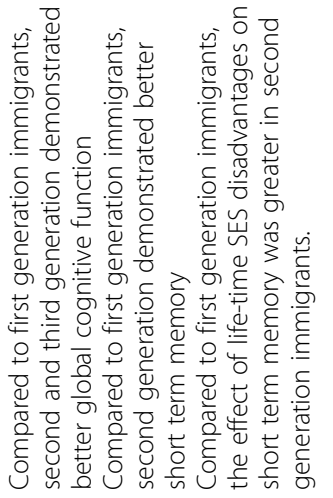
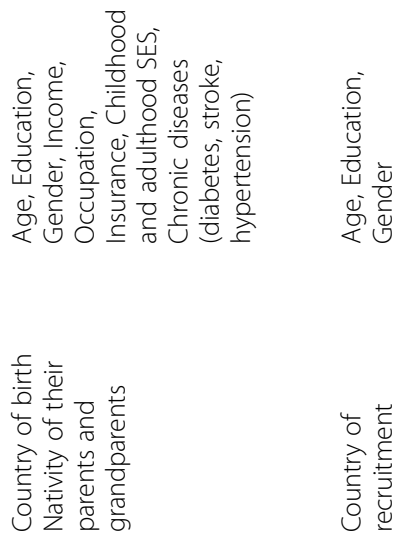

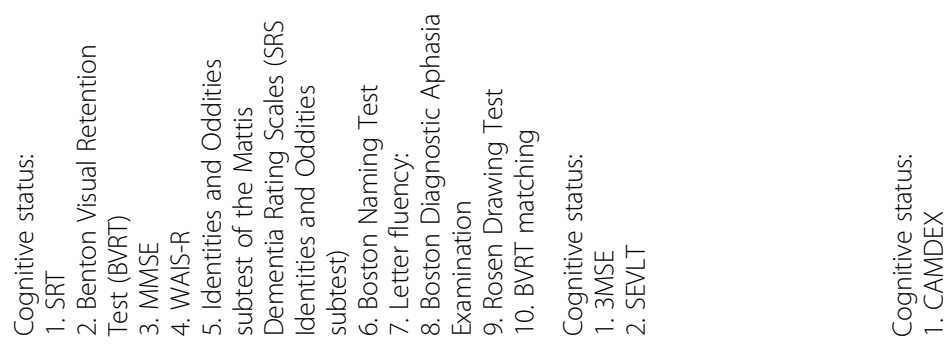

ত্ّ

岕

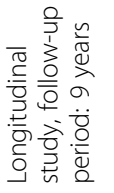

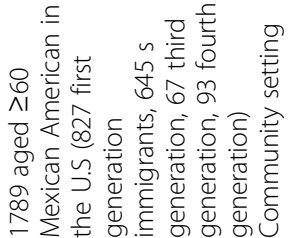




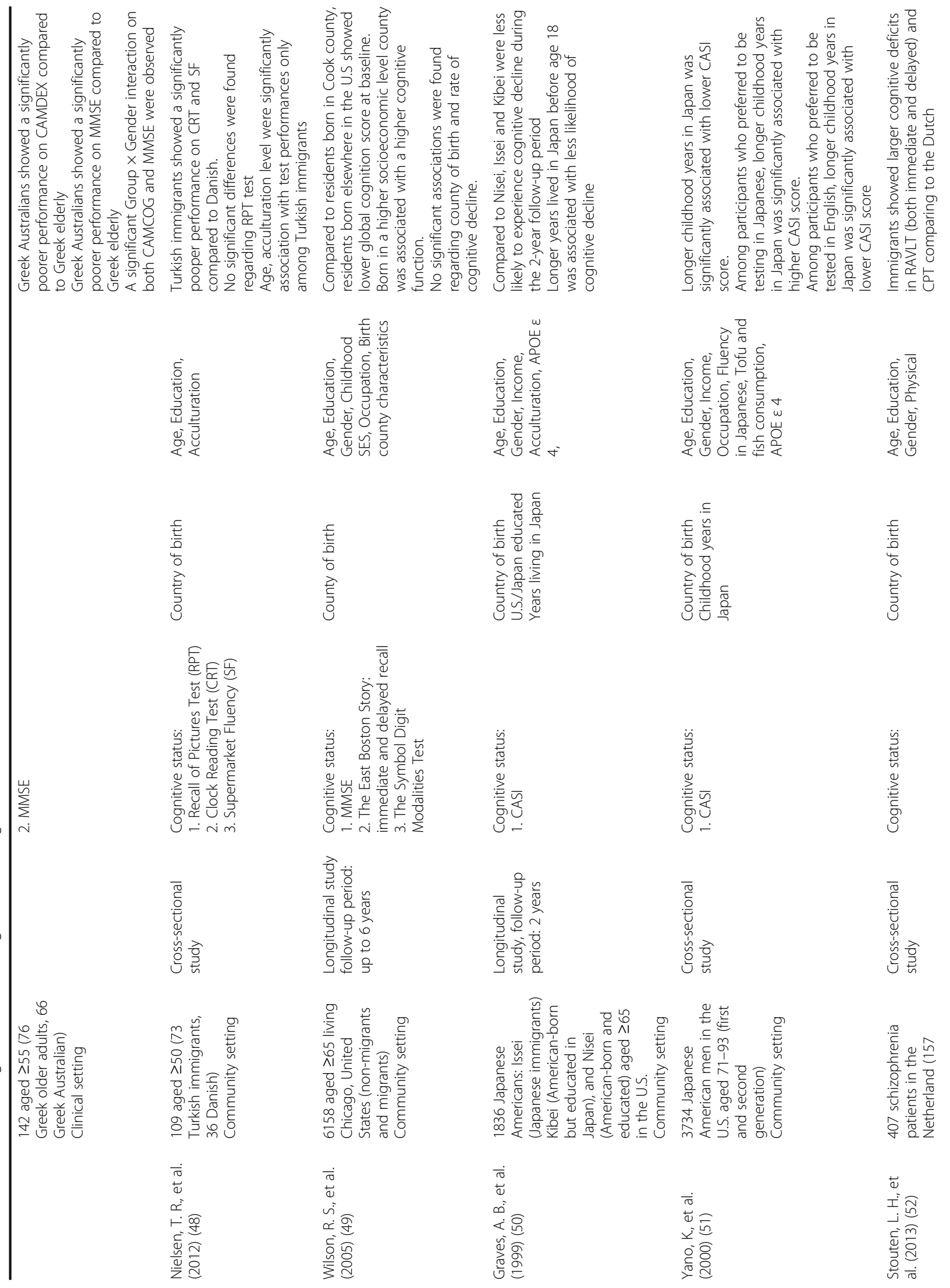




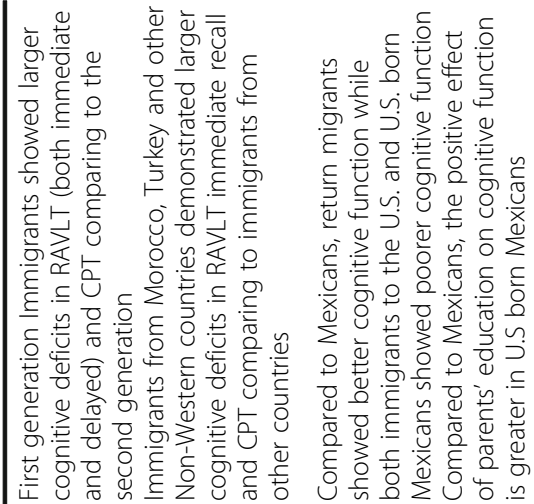

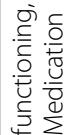

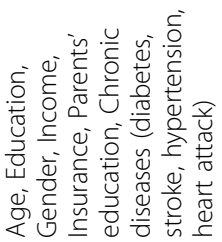

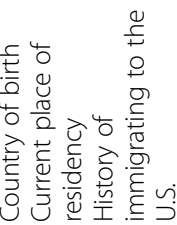
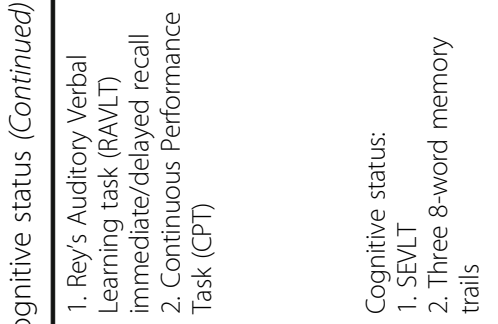

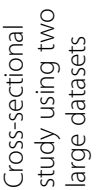

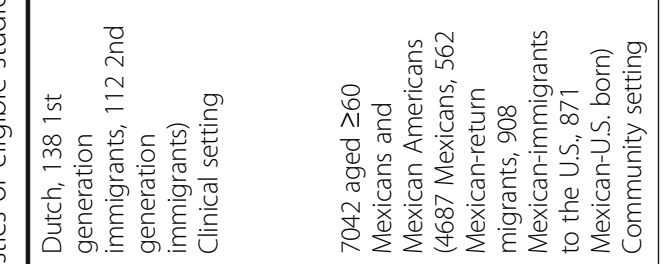

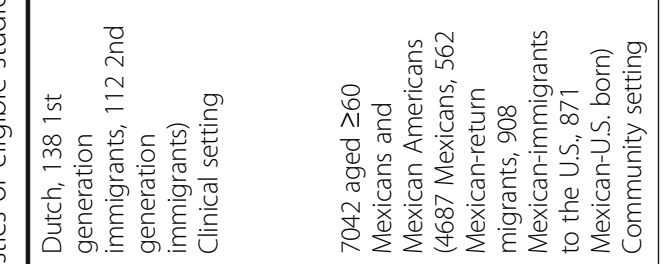

들

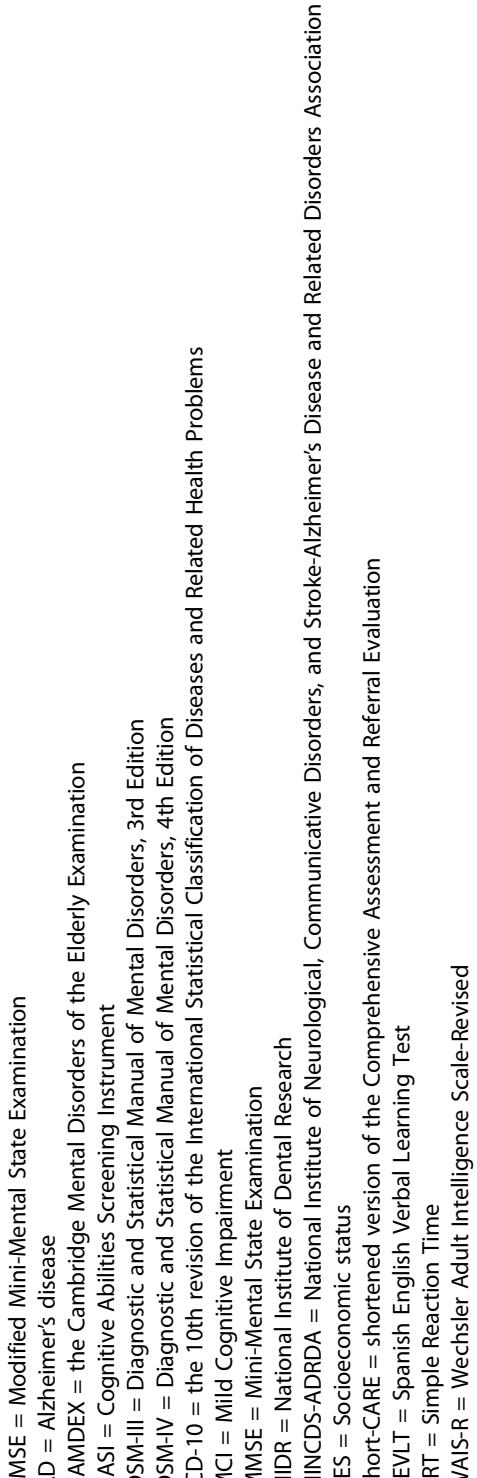

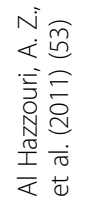

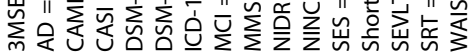


applied a two-stage cognitive function assessment in which participants were initially screened and then received clinical evaluation of dementia [30, 38-41].

Two studies applied standard diagnostic criteria for dementia DSM-III [31, 42] and one used DSM-IV and ICD10 [28]. Other criteria included NINCDS-ADRDA for Alzheimer's disease [28, 30, 36] and NINDS-AIREN for vascular dementia $[28,36]$. Only one study used the shortened version of the Comprehensive Assessment and Referral Evaluation (Short-CARE) to identify persons with dementia [43]. Three studies did not specify the criteria that was used for dementia diagnosis [38, 40, 41].

The most widely used single measure of cognitive status is the MMSE, and this was used in 14 studies [44], one of which adapted the orientation questions from the MMSE as part of the neuropsychology measures [45]. One study from India used the Hindi Mental State Examination, a modified version of the MMSE to make the instrument culturally appropriate [38]. At times other instruments including the Modified Mini Mental Status Exam (3MSE) [36, 46] and the Cambridge Mental Disorders of the Elderly Examination (CAMDEX) [28, 39, 47] were used to measure individuals' global cognitive function. Six studies applied a substantial cognitive battery to assess different aspects of cognitive function [31, 45, 48, 49]. All the measures used in the 25 studies, including both clinical diagnostic tools and epidemiological screening measures, were shown to be valid and reliable.

\section{Measures of migration}

Among the 22 studies that focused on immigration, 21 identified immigrants based on whether they were born in the receiving country. Only one study conducted in Canada defined immigrants as those whose first language was neither English nor French [30]. Nineteen studies included information on country of birth, 6 of which asked participants their age at immigration or length of stay in the receiving country $[29,31,32,45,50,51]$.

Three studies focused on internal migrants. Two studies conducted in India did not specify the definition of migrants $[38,41]$. The third study defined migrants to be individuals who lived in Cook County, Illinois, but were born elsewhere [49]. None of the 25 articles assessed the reason for migration.

\section{Covariates included in the analyses}

Twenty-one articles included some of the sociodemographic characteristics (e.g. age, gender, and education) as covariates in the analyses. Other common covariates included functional disability [32, 34, 52], chronic disease [32-35, 43, 46, 52, 53], health behaviors $[32,43,51]$, depressive symptoms [32-34], and early- and middle-life socioeconomic conditions [35, 46, 49]. Two studies included environmental factors at neighborhood [35] or county level [49]. The genetic biomarker APOE $\varepsilon 4$ was also considered in two studies $[50,51]$.

\section{Findings \\ Comparisons between immigrants and residents in hosting countries}

Nine studies compared first-generation with secondgeneration immigrants regarding their cognitive function, and one of those studies also included third- and fourthgeneration immigrants [46]. Four of them indicated no significant differences between first-generation and second-generation immigrants in cognitive function at baseline or the rate of cognitive decline [34, 35, 51, 53]. This result was contradicted by other studies that showed differences in cognitive function between first- and futuregeneration immigrants $[32,33,46,50,52]$. Further, findings were inconsistent among these five studies. Four studies showed that first-generation immigrants demonstrated poorer cognitive function [33, 46, 52] than second- and even the third-generation immigrants. However, one study indicated that firstgeneration Japanese immigrants were less likely to experience cognitive decline than the second-generation immigrants [50]. Another study found the association between immigration and cognitive function varied by gender and age at immigration [32]. Hill et al. [32] showed that male Mexican American immigrants who migrated to the United States in their middle age showed both better cognitive function at baseline as well as a slower decline rate compared to U.S-born Mexican American men. Immigration status and age at immigration were not significantly associated with both baseline cognitive functioning and the cognition trajectories among the female population [32].

Four studies found that immigrants had poorer cognitive function compared to individuals in hosting countries that are native-born residents [39, 40, 45, 48, 52]. One study showed that a higher proportion of immigrants scored as "cognitively impaired" measured by the CAMDEX [39]. Still, two studies showed no difference in cognitive function between immigrants and native-born residents [29, 30].

Four studies examined the association between immigration and incidence of dementia [28, 30, 36, 43]. Two studies conducted in the UK reported a higher prevalence of dementia among African-Caribbean immigrants than those born in the UK [28, 43]. The other two studies that focused on persons with dementia showed no significant association between immigrant status and age of dementia diagnosis [30, 36]. In addition, these two studies explored the interaction between bilingualism and immigration and their possible effects on age of dementia diagnosis. Lawton 
et al. [36] found no significant interaction effect while the other study showed that native English monolinguals were diagnosed with dementia at a later age than immigrant monolinguals [30].

\section{Comparisons between immigrants and residents in sending countries}

Three studies compared immigrants versus residents in their sending countries $[37,47,53]$. Two cross sectional studies compared local Mexican residents to Mexicans who immigrated to the United States; the results of these two studies contradicted each other. One cross-sectional study that used several different data sources found that the prevalence of cognitive impairment was similar among Mexican immigrants and Mexicans [37]. However, the other study demonstrated that compared to Mexicans, both immigrants to the United States and U.S-born Mexicans had poorer cognitive function [53]. This study also found that return migrants from the United States showed better cognitive function than local residents in Mexico [53]. The third study conducted in Australia also reported poorer cognitive function among Greek Australians compared to their counterparts living in Greece [47].

\section{Comparisons across immigrant groups}

Four studies made comparisons across different immigrant populations in the same hosting country $[29,31,40,42]$. Two of them found no significant difference in cognitive function among immigrants from various countries $[29,42]$. But these results were contradicted by two other studies. One study conducted in Belgium showed that compared to European immigrants, non-European immigrants had poorer cognitive function measured by the MMSE and were more likely to have Parkinson's-related cognitive disorders [40]. The other study found immigrants in the U.S. from the Dominican Republic/Puerto Rico showed poorer initial performance on memory and language tests, but not the rate of change in any cognitive domains between Dominican Republic/Puerto Rican immigrants and immigrants from other countries [31].

\section{Comparisons among internal migrants and non-migrants}

Three studies examined the association between internal migration and cognitive function, two of which indicated migrants had poorer cognitive function than nonmigrants $[41,49]$. Another study from India showed that urban residents had a higher prevalence of cognitive impairment than rural and migrant population in India [38]. However, no statistically significant differences were found in the prevalence of cognitive impairment between rural and migrant population [38].

\section{Findings from longitudinal studies}

Using longitudinal data, several studies found no significant differences in the rate of cognitive decline between migrants and non-immigrants $[29,30,34,35,49]$, or between immigrants from different countries of origin $[29,31]$. However, two studies demonstrated a protective effect of migration on cognitive decline $[32,50]$.

\section{Assessment of the quality of the eligible studies}

Each of the studies was assessed using a set of criteria developed earlier, including sample selection, sample size, validated assessment of outcome, attrition, conflict of interests report, and analytic approach $[54,55]$. The evaluation of each article suggested methodological deficiencies in this area of research. The most problematic aspects included baseline incomparability (e.g. significant differences in sample characteristics between migrants and non-migrants, $n=25$ ), inadequate assessment of cognitive function (e.g. only used a screening tool such as MMSE to measure cognitive function, $n=17$ ), lack of longitudinal studies $(n=16)$, inadequacy in addressing incomplete data (e.g. no information on missing data management, $n=16$ ), and high dropout rate (e.g. dropout rate $=35 \%, n=19$ ). Therefore, the current evidence was low quality and therefore systematic conclusions cannot be made. Detailed results are available from the authors upon request.

\section{Discussion}

This is the first systematic review that examined the association between migration and cognitive function. A total of 25 articles were identified with 22 immigration studies and another 3 studies focused on internal migration. The results from the review showed inconsistent associations between migration and cognitive function. For example, some studies found a significant negative association, albeit relatively weak, between migration and cognitive function; but other studies found no association. This may largely due to the wide variation in the study design, sample size, sample characteristics, and measures across studies. More importantly, it would be essential to include the reasons for migration because this may have implications for individual's financial status, social support, sense of well-being, and health status including cognitive function. Because of the inconclusive finding, we didn't discuss the potential implications for clinical practices and health policies.

Most studies compared migrants with people in hosting countries and some demonstrated that immigrants had poorer cognitive function. It is possible that the disparities in cognitive function between migrants and non-migrants could be partially explained by low level of acculturation, such as poor language skills. Several studies found that immigrants who had better acquisition of the language 
that the cognition test was conducted in (i.e. the language used in the hosting countries) showed better cognitive function [31, 33, 47, 48, 51]. Language is associated with some domains of cognitive function. When studying cognitive function among immigrant population, we need to be aware whether the proficiency of certain language may bias the test results. Thus, it would even be more important to use longitudinal studies to compare the changes in cognitive function among immigrant population, in comparison with the native-born population in hosting countries.

Another possible explanation is SES pathway as we described in the introduction. Immigrants are likely to have the disadvantages in SES, especially Hispanic immigrants, compared with the native-born population. Several studies reported that immigrants tended to have a lower level of education and more financial strains than residents in hosting countries [32, 33, 46, 48, 53]. In addition, migrants didn't necessarily have better SES compared to non-migrants in the sending countries $[47,53]$. It might due the incomparability in SES measures such as the quality of education and wages standards between hosting and sending countries $[47,53]$. Previous research showed strong association between SES and cognitive function [56]. Education has been shown to positively influence an individual's cognitive function in late life [11]. Moreover, SES benefits may lead to improvement in health service utilization and better care of chronic conditions, which are associated with an individual's cognitive function [12].Therefore, the SES disadvantage may partially contribute to poorer cognitive function among immigrant populations. However, the SES disadvantage pathway may only apply for the Hispanic immigrant populations. Studies that focused on immigrants from Japan showed no significant difference in SES between Japanese immigrants and Japanese Americans $[50,51]$. One study that compared Mexican-return migrants with Mexicans found better SES among Mexicanreturn migrants, which might be explained by the observed SES advantages among Mexican-return migrants [53].

In addition, as we expected, some studies suggested that migration-related life style changes may serve as mediators that link migration and cognitive function. For example, studies showed Japanese immigrants who preferred traditional Japanese diet were more likely to have better cognitive function $[50,51]$. This may because traditional Japanese diet was associated with fewer chronic diseases that were risk factors of cognitive decline [51]. Similarly, one study that compared Mexicans versus Mexican Americans found better cognitive function among Mexicans [53]. One explanation is that Mexicans showed healthier life styles and better chronic disease profiles, which are protective against cognitive decline [53].

Some other studies argue that migrants who come from unfavorable early-life socioeconomic positions may have residual negative effects on later-life cognitive function [32, 35, 42, 46, 49, 52]. However, results from limited studies controlled for early-life socioeconomic status (three out of 25), and studies that compared immigrants and non-migrants from sending countries are inconsistent. Therefore, whether migration could buffer the negative effects of early-life disadvantage on cognitive function is inconclusive.

With the aging population increasing, the burden of cognitive impairment and dementia is expected to increase. In the meantime, the migrant population, especially internal migrants in developing countries, is increasing dramatically. Research on the association between migration and cognitive function is still in the early stages, which results in many potential implications for future research.

To better examine the association between migration and cognitive function, more comprehensive measures of the migration process are needed. Most of previous studies defined migration status based on birth place and current living place, which is a rather crude method. Only 6 studies measured age at immigration or length of stay in the receiving country $[29,31,32,45,50,51]$. However, no studies included information on participants' reasons for migration (e.g., education, family reunion, economic condition, and political asylum). Refugees and people who migrated for the purpose of better education are likely to have different SES, psychosocial distress, and/or health status which may affect the level of cognitive function. Therefore, without knowing the whole picture of the migration process, it would be difficult to identify the specific aspects of migration that might influence an individual's cognitive function. Therefore, including more detailed information on the migration history is necessary for future research. In addition, qualitative studies would be useful because they allow researchers to use in-depth interviews to capture the migration process of each individual, and the resulting data could supplement quantitative studies.

In addition, future research should include more sensitive, valid and culturally appropriate clinical measures of cognitive impairment and dementia. Only 8 articles used validated clinical instrument to measure cognitive function and the MMSE [44] is the most frequently used measure in literature especially among population-based studies. However, research has shown the ceiling and floor effects of this instrument in detecting cognitive decline [57, 58]. Additional tests are recommended to detect possibility of mild cognitive impairment (MCI) or dementia. In addition, future studies should apply culturally specific versions of cognitive function measures to ensure their reliability and validity. Participants who are immigrants should be tested in their preferred language. Although the MMSE has multiple language versions, the 
comparability among them remains unknown. Therefore, future research should consider using measures such as the Montreal Cognitive Assessment that are sensitive to changes in cognitive function and could accommodate certain linguistic and cultural differences [59].

Evaluation of the study quality suggested that there were methodological deficiencies in the current literature about migration and cognitive function. Only 9 studies applied longitudinal design [29-32, 34, 35, 46, 49, 50], 9 adequately addressed incomplete data [30-32, 45, 46, 48-50, 53], and 6 had a dropout rate $<30 \%[28,31,32,46,49,50]$. These deficiencies are likely to produce biased results and limit the generalizability of the study findings. From a lifecourse perspective, the impact of migration or migration related changes can accumulate throughout the life-course. We also noticed that studies with higher quality tend to find differences in cognitive function (either baseline or slope differences) between migrants and non-migrants. Therefore, more longitudinal studies using validated measures and appropriate control are essential to establish a strong association between migration and cognitive function.

A large variety of covariates were reported in the previous studies, including demographic characteristics, health behaviors and health status. Still, only adjusting for these covariates may not be sufficient. Results from our quality assessment indicated that migrants and nonmigrants had relatively different characteristics. It is possible that some differences in level of cognition between migrants and non-migrants are likely to be explained by confounding variables other than migration status. Thus, using more sophisticated statistical methods should be encouraged to adjust for confounding factors. For example, using propensity scores, researchers are able to balance the distributions of observed covariates between treatment conditions (e.g. rural residents and rural-tourban migrants) so that a direct comparison between matched treatment conditions becomes valid [60]. Another solution is to use instrumental variable analysis to minimize the unmeasured cofounding factors [61]. Additionally, several other factors that are associated with cognitive function and migration were rarely included in the literature. For example, migrants are likely to experience changes in psychosocial factors such as social support and social network during and after the migration process [23]. Some studies found social isolation to be a risk factor for cognitive impairment and cognitive decline $[26,62,63]$, and many migrants face the challenge of decreasing social network. In addition, studies have shown that stressful life events are associated with increased dementia risk $[64,65]$. However, none of the included studies controlled for these psychosocial factors, which should be considered in future research.
Only three studies have been conducted to assess the cognitive function among internal migrants. Given the tremendous increase in rural-to-urban migrant population globally, it is important to examine the association between internal migration and cognition using longitudinal data. Research in this area will provide new knowledge on health disparities particularly among rural residents and rural-to-urban migrants. Comparisons across three groups (i.e., rural residents, urban residents, and rural-to-urban migrants) will allow researchers to study the environmental differences and health disparities between rural and urban areas and understand the impact of rural-to-urban migration on health status in later life. If such disparities exist, research that assesses health disparities should not only compare health status differences between rural and urban residents, but also consider the migrant group.

\section{Conclusion}

Overall, the evidence from current studies regarding the association between migration and cognitive function is weak and inconclusive. Findings were inconsistent across studies, and the association ranged from a negative association, to no association, to a positive association (albeit, in only one study). The quality of current literature suffered from methodological deficiencies, with limited studies applying longitudinal design, using validated outcome measures, addressing potential selection bias adequately. Additional research is needed to examine the linkages using more rigorous study design and validated instruments.

\section{Abbreviations \\ 3MSE: Modified Mini-Mental State Examination; AD: Alzheimer's disease; CAMDEX: the Cambridge Mental Disorders of the Elderly Examination; CASI: Cognitive Abilities Screening Instrument; DSM-III: Diagnostic and Statistical Manual of Mental Disorders, 3rd Edition; DSM-IV: Diagnostic and Statistical Manual of Mental Disorders, 4th Edition; ICD-10: the 10th revision of the International Statistical Classification of Diseases and Related Health Problems; MCl: Mild Cognitive Impairment; MMSE: Mini-Mental State Examination; NIDR: National Institute of Dental Research; NINCDS- ADRDA: National Institute of Neurological, Communicative Disorders, and Stroke-Alzheimer's Disease and Related Disorders Association; SES: Socioeconomic status; SEVLT: Spanish English Verbal Learning Test; Short-CARE: shortened version of the Comprehensive Assessment and Referral Evaluation; SRT: Simple Reaction Time; WAIS-R: Wechsler Adult Intelligence Scale-Revised}

\section{Acknowledgements}

This study was presented at the 2016 Annual Meeting of the Gerontological Society of America.

\section{Funding}

The authors declare that they have no funding support for this study.

Availability of data and materials

All data generated or analysed during this study are included in this published article. 


\section{Disclaimer}

Views expressed in the paper are solely of those authors and do not necessarily reflect those of Duke University, Chinese Center for Health Education, and New York University.

\section{Authors' contributions}

$H X$ designed, drafted, and revised the manuscript. HX and YZ contributed to the extraction of data and data analysis. YZ and BW contributed to the critical revision of the manuscript. All authors have approved the final version of the manuscript.

\section{Ethics approval and consent to participate}

This article does not contain any data with human subjects or animals performed by any of the authors.

\section{Consent for publication}

Not applicable.

\section{Competing interests}

The authors declare that they have no competing interests.

\section{Publisher's Note}

Springer Nature remains neutral with regard to jurisdictional claims in published maps and institutional affiliations.

\section{Author details}

'Duke University School of Nursing, Durham, NC, USA. ${ }^{2}$ Duke Global Health Institute, Duke University Medical Center, Durham, NC, USA. ${ }^{3}$ Chinese Center for Health Education, Beijing, China. ${ }^{4}$ New York University Rory Meyers College of Nursing, New York, NY, USA.

\section{Received: 3 January 2017 Accepted: 9 August 2017}

\section{Published online: 17 August 2017}

\section{References}

1. International Organization for Migration. World Migration Report. 2015.

2. United Nations Department of Economic and Social Affairs. Global Migration: Demographic Aspects and Its Relevance for Development. 2013;

3. Treas J, Gubernskaya Z. Handbook of aging and the social sciences. Sci: Handb. Aging Soc; 2016.

4. Prince M, Wimo A, Guerchet M, Gemma-Claire A, Wu Y-T, Prina M, World Alzheimer Report. The global impact of dementia - an analysis of prevalence, incidence, cost and trends. Alzheimer's Dis Int. 2015;2015:84

5. Tong Y, Piotrowski M. Migration and health selectivity in the context of internal migration in China, 1997-2009. Popul Res Policy Rev. 2012;31:497-543.

6. Spallek J, Zeeb H, Razum O. What do we have to know from migrants' past exposures to understand their health status? A life course approach. Emerg Themes Epidemiol. 2011:8:6.

7. Koster A, Penninx BWJH, Bosma H, Kempen GIJM, Newman AB, Rubin SM, et al. Socioeconomic differences in cognitive decline and the role of biomedical factors. Ann Epidemiol. 2005;15:564-71.

8. Deary IJ, Corley J, Gow AJ, Harris SE, Houlihan LM, Marioni RE, et al. Ageassociated cognitive decline. Br Med Bull. 2009;92:135-52.

9. Potter GG, Plassman BL, Helms MJ, Foster SM, Edwards NW. Occupational characteristics and cognitive performance among elderly male twins. Neurology. 2006;67:1377-82.

10. Gow AJ, Avlund K, Mortensen EL. Occupational characteristics and cognitive aging in the Glostrup 1914 cohort. Journals Gerontol. - Ser. B Psychol. Sci. Soc. Sci. 2014;69:228-36.

11. Zhao Y. Leaving the countryside: rural-to-urban migration decisions in China. Am Econ Rev. 1999;89:281-6.

12. Tuligenga RH, Dugravot A, Tabák AG, Elbaz A, Brunner EJ, Kivimäki M, et al. Midlife type 2 diabetes and poor glycaemic control as risk factors for cognitive decline in early old age: a post-hoc analysis of the Whitehall II cohort study. Lancet Diabetes Endocrinol. 2014;2:228-35.

13. Ginsburg C, Griffiths PL, Richter LM, Norris SA. Residential mobility, socioeconomic context and body mass index in a cohort of urban south African adolescents. Health Place. 2013;19:99-107.

14. Landman J, Cruickshank JK. A review of ethnicity, health and nutritionrelated diseases in relation to migration in the United Kingdom. Public Health Nutr. 2001;4:647-57.
15. Zezza A, Carletto C, Davis B, Winters P. Assessing the impact of migration on food and nutrition security. Food Policy. 2011;36:1-6.

16. Torun B, Stein AAD, Schroeder D, Grajeda R, Conlisk A, Rodriguez M, et al. Rural-to-urban migration and cardiovascular disease risk factors in young Guatemalan adults. Int J Epidemiol. 2002;31:218-26.

17. Popkin BM. The nutrition transition in low-income countries: an emerging crisis. Nutr Rev. 1994;52:285-98.

18. Steyn K, Kazenellenbogen JM, Lombard CJ, Bourne LT. Urbanization and the risk for chronic diseases of lifestyle in the black population of the cape peninsula. South Africa J Cardiovasc Risk. 1997;4:135-42.

19. Taylor R, Badcock J, King H, Pargeter K, Zimmet P, Fred T, et al. Dietary intake, exercise, obesity and noncommunicable disease in rural and urban populations of three Pacific Island countries. J Am Coll Nutr. 1992;11:283-93.

20. Sabia S, Elbaz A, Dugravot A, Head J, Shipley M, Hagger-Johnson G, et al. Impact of smoking on cognitive decline in early old age: the Whitehall II cohort study. Arch Gen Psychiatry. 2012;69:627-35.

21. Afable-Munsuz A, Mayeda ER, Pérez-Stable EJ, Haan MN. Immigrant generation and diabetes risk among Mexican Americans: the Sacramento area Latino study on aging. Am. J. Public Health. 2014;104 Suppl:S234-S250.

22. Buja A, Gini R, Visca M, Damiani G, Federico B, Francesconi P, et al. Prevalence of chronic diseases by immigrant status and disparities in chronic disease management in immigrants: a population-based cohort study. Valore Project BMC Public Health. 2013;13:504.

23. Lu Y, Hu P, Treiman DJ. Migration and depressive symptoms in migrantsending areas: findings from the survey of internal migration and health in China. Int J Public Health. 2012;57:691-8.

24. Haug S. Migration networks and migration decision-making. J Ethn Migr Stud. 2008;34:585-605.

25. Dancygier RM, Laitin DD. Immigration into Europe: economic discrimination, violence, and public policy. Annu Rev Polit Sci. 2014;17:43-64

26. Shankar A, Hamer M. Social isolation and loneliness: relationships with cognitive function during 4 years of follow-up in the English Longitudinal Study of Ageing. Psychosom Med. 2013;75(2):161-70.

27. Moher D, Liberati A, Tetzlaff J, Altman DG. Preferred reporting items for systematic reviews and meta-analyses: the PRISMA statement. Ann Intern Med. 2009:151:264-9. W64

28. Adelman S, Blanchard M, Rait G, Leavey G, Livingston G. Prevalence of dementia in African-Caribbean compared with UK-born white older people: two-stage cross-sectional study. Br J Psychiatry. 2011;199:119-25.

29. Kave G, Eyal N, Shorek A, Cohen-Mansfield J. Multilingualism and cognitive state in the oldest old. Psychol Aging. 2008/03/26. 2008;23:70-78.

30. Chertkow H, Whitehead V, Phillips N, Wolfson C, Atherton J, Bergman H. Multilingualism (but not always bilingualism) delays the onset of Alzheimer disease: evidence from a bilingual community. Alzheimer Dis Assoc Disord. 2010:24:118-25

31. Zahodne LB, Schofield PW, Farrell MT, Stern Y, Manly JJ. Bilingualism does not alter cognitive decline or dementia risk among Spanish-speaking immigrants. Neuropsychology. 2014;28:238-46.

32. Hill TD, Angel JL, Balistreri KS, Herrera AP. Immigrant status and cognitive functioning in late-life: an examination of gender variations in the healthy immigrant effect. Soc Sci Med. 2012/05/23. 2012;75:2076-2084.

33. Black SA, Espino DV, Mahurin R, Lichtenstein MJ, Hazuda HP, Fabrizio D, et al. The influence of noncognitive factors on the mini-mental state examination in older Mexican-Americans: findings from the Hispanic EPESE. J Clin Epidemiol. 1999:52:1095-102.

34. Nguyen HT, Black SA, Ray LA, Espino D V, Markides KS. Predictors of decline in MMSE scores among older Mexican Americans. J Gerontol A Biol Sci Med Sci. 2002/02/28. 2002;57:M181-M185.

35. Sheffield KM, Peek MK. Neighborhood context and cognitive decline in older Mexican Americans: results from the Hispanic Established Populations for Epidemiologic Studies of the Elderly. Am J Epidemiol. 2009/03/10. 2009:169:1092-1101.

36. Lawton DM, Gasquoine PG. Weimer AA. Cortex: Age of dementia diagnosis in community dwelling bilingual and monolingual Hispanic Americans; 2015.

37. Mejia S, Miguel A, Gutierrez LM, Villa AR, Ostrosky-Solis F. Comparative analysis of cognitive impairment among Mexicans and Spanish-speaking immigrant's elders. J Aging Heal. 2006/04/15. 2006;18:292-314.

38. Raina SK, Raina S, Chander V, Grover A, Singh S, Bhardwaj A. Is dementia differentially distributed? A study on the prevalence of dementia in migrant, urban, rural, and tribal elderly population of Himalayan region in northern India. N Am J Med Sci. 2014;6:172-7. 
39. Lindesay J, Jagger C, Mlynik-Szmid A, Sinorwala A, Peet S, Moledina F. The mini-mental state examination (MMSE) in an elderly immigrant Gujarati population in the United Kingdom. Int J Geriatr Psychiatry. 1997;12:1155-67.

40. Segers K, Benoit F, Colson C, Kovac V, Nury D, Vanderaspoilden V. Pioneers in migration, pioneering in dementia: first generation immigrants in a European metropolitan memory clinic. Acta Neurol Belg. 2013;113:435-40.

41. Raina SK, Razdan S, Pandita KK. Prevalence of dementia in ethnic Dogra population of Jammu district, North India: a comparison survey. Neurol Asia. 2010;15:65-9.

42. Kahana E, Galper Y, Zilber N, Korczyn AD. Epidemiology of dementia in Ashkelon: the influence of education. J Neurol. 2003;250:424-8.

43. Livingston G, Leavey G, Kitchen G, Manela M, Sembhi S, Katona C. Mental health of migrant elders-the Islington study. Br J Psychiatry. 2001/10/03. 2001;179:361-366.

44. Folstein M, Folstein S, McHugh P. "mini-mental state": a practical method for grading the cognitive state of patients for the clinician. J Psychiatr Res. 1975;12(3):189-98.

45. Touradj P, Manly JJ, Jacobs DM, Stern Y. Neuropsychological test performance: a study of non-Hispanic White elderly. J Clin Exp Neuropsychol. 2002/01/10. 2001;23:643-649.

46. Haan MN, Zeki Al-Hazzouri A, Aiello AE. Life-span socioeconomic trajectory, nativity, and cognitive aging in Mexican Americans: the Sacramento Area Latino Study on Aging. J. Gerontol. B. Psychol. Sci. Soc. Sci. 2011:66 Suppl 1:i102-i110.

47. Plitas A, Tucker A, Kritikos A, Walters I, Bardenhagen F. Comparative study of the cognitive performance of Greek Australian and Greek national elderly: implications for neuropsychological practice. Aust. Psychol. Malden, Massachusetts: Wiley-Blackwell. 2009;44:27-39 13p.

48. Nielsen TR, Vogel A, Waldemar G. Comparison of performance on three neuropsychological tests in healthy Turkish immigrants and Danish elderly. Int. Psychogeriatrics. Cambridge University Press. 2012;24:1515-1521 7p.

49. Wilson RS, Scherr PA, Bienias JL, Mendes de Leon CF, Everson-Rose SA Bennett DA, et al. Socioeconomic characteristics of the community in childhood and cognition in old age. Exp Aging Res. 2005/09/09. 2005;31:393-407.

50. Graves AB, Rajaram L, Bowen JD, WC MC, SM MC, Larson EB. Cognitive decline and Japanese culture in a cohort of older Japanese-Americans in King County, WA: The Kame Project. Journals Gerontol. Ser. B Psychol. Sci. Soc. Sci. US: Gerontological Society of America. 1999;54B:S154-61.

51. Yano K, Grove JS, Masaki KH, White LR, Petrovitch $H$, Chen R, et al. The effects of childhood residence in Japan and testing language on cognitive performance in late life among Japanese American men in Hawaii. J Am Geriatr Soc. 2000/02/22. 2000;48:199-204.

52. Stouten $\mathrm{LH}$, Veling W, van der Helm M, Laan W, van der Gaag M. Cognitive deficits and ethnicity: a cohort study of early psychosis patients in The Netherlands. Soc Psychiatry Psychiatr Epidemiol. 2013;48:37-47.

53. Al Hazzouri AZ, Haan MN, Galea S, Aiello AE, Zeki Al Hazzouri A, Haan MN, et al. Life-course exposure to early socioeconomic environment, education in relation to late-life cognitive function among older Mexicans and Mexican Americans. J Aging Heal. 2011/09/29. 2011;23:1027-1049.

54. Wu B, Fillenbaum GG, Plassman BL, Guo L. Association between oral health and cognitive status: a systematic review. J Am Geriatr Soc. 2016;64:739-51.

55. Williams JW, Plassman BL, Burke J, Holsinger T, Benjamin S. Preventing Alzheimer's Disease and Cognitive Decline: Evidence Report/Technology Assessment No. 193. Rockville, MD: Agency for Healthcare Research and Quality; 2010. AHRQ publication 10-E005.

56. Cagney KA, Lauderdale DS. Education, wealth, and cognitive function in later life. J. Gerontol. B. Psychol. Sci. Soc. Sci. 2002;57:P163-72.

57. Arevalo-Rodriguez I, Smailagic N, Roqué I, Figuls M, Ciapponi A, SanchezPerez E, Giannakou A, et al. Mini-mental state examination (MMSE) for the detection of Alzheimer's disease and other dementias in people with mild cognitive impairment (MCI). Cochrane Database Syst Rev. 2015;3:CD010783.

58. Hoops S, Nazem S, Siderowf AD, Duda JE, Xie SX, Stern MB, et al. Validity of the MoCA and MMSE in the detection of $\mathrm{MCl}$ and dementia in Parkinson disease. Neurology. 2009;73:1738-45.

59. Nasreddine Z, Phillips N. The Montreal Cognitive Assessment, MoCA: a brief screening tool for mild cognitive impairment. J. .... 2005;

60. McCaffrey DF, Griffin BA, Almirall D, Slaughter ME, Ramchand R, Burgette LF A tutorial on propensity score estimation for multiple treatments using generalized boosted models. Stat Med. 2013;32:3388-414
61. Nguyen TT, Tchetgen EJT, Kawachi I, Gilman SE, Walter S, Liu SY, et al. Instrumental variable approaches to identifying the causal effect of educational attainment on dementia risk. Ann. Epidemiol. 2016;26:71-76.e3.

62. DiNapoli EA, Wu B, Scogin F. Social isolation and cognitive function in Appalachian older adults. Res Aging. 2014;36:161-79.

63. Crooks VC, Lubben J, Petitti DB, Little D, Chiu V. Social network, cognitive function, and dementia incidence among elderly women. Am J Public Health. 2008;98:1221-7.

64. Norton MC, Smith KR, Østbye T, Tschanz JT, Schwartz S, Corcoran C, et al. Early parental death and remarriage of widowed parents as risk factors for Alzheimer disease: the Cache County study. Am J Geriatr Psychiatry. 2011;19:814-24.

65. Tschanz JT, Pfister R, Wanzek J, Corcoran C, Smith K, Tschanz BT, et al. Stressful life events and cognitive decline in late life: moderation by education and age. The Cache County study. Int. J. Geriatr. Psychiatry. 2013;28:821-30

\section{Submit your next manuscript to BioMed Central and we will help you at every step:}

- We accept pre-submission inquiries

- Our selector tool helps you to find the most relevant journal

- We provide round the clock customer support

- Convenient online submission

- Thorough peer review

- Inclusion in PubMed and all major indexing services

- Maximum visibility for your research

Submit your manuscript at www.biomedcentral.com/submit
Biomed Central 